
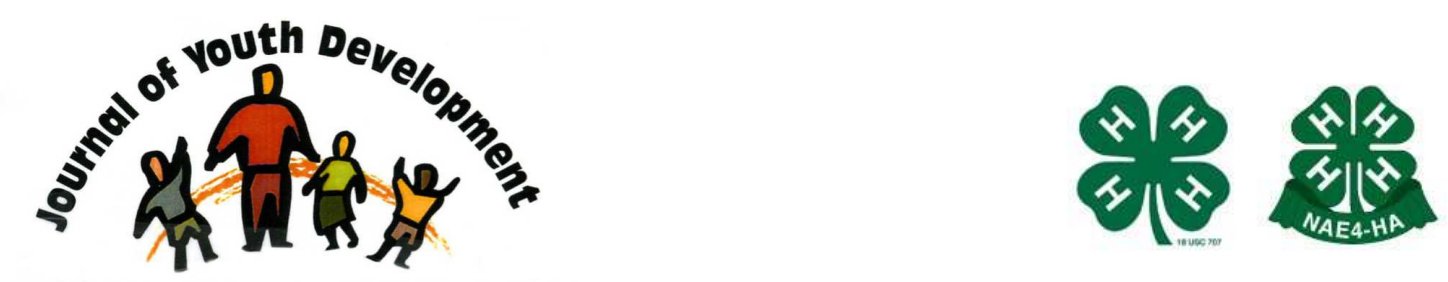

Bridging Research \& Practice

\title{
Structural Social Work Lens: \\ A View of Youth Engagement in the Social Policy Life of their Communities
}

\author{
Donna Hardy Cox \\ School of Social Work \\ Memorial University of Newfoundland \\ St. John's, NL \\ Canada A1C 5S \\ dhardy@mun.ca \\ E. Michelle Sullivan \\ School of Social Work \\ Memorial University of Newfoundland \\ St. John's, NL \\ Canada A1C 5S \\ Nancy E. Sullivan \\ School of Social Work \\ Memorial University of Newfoundland \\ St. John's, NL \\ Canada A1C 5S
}




\title{
JOURNAL OF YOUTH DEVELOPMENT \\ bridging research and practice

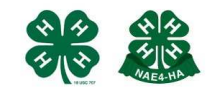

Volume 5, Number 2, Summer 2010

Article 100501FA003

\section{Structural Social Work Lens: A View of Youth Engagement in the Social Policy Life of their Communities}

\author{
Donna Hardy Cox, E. Michelle Sullivan and Nancy E. Sullivan \\ Memorial University of Newfoundland
}

\begin{abstract}
Presented through a structural social work lens, this paper is a description and analysis of an action research project designed to explore factors that encourage or impede the engagement of youth in the social policy life of their communities. The project was conceptualized in a geographic region characterized by the erosion of community sustainability due to social economic disadvantage and out migration. The project aimed to strengthen communities by enhancing participation of youth in social policy development. It utilized a workshop designed and delivered by youth for youth and the development a Social Policy Action Plan (SPAP) to address a policy issue of concern in youth's local community. Principles of structural social work, with particular attention to power sharing, unmasking the structures, collective consciousness, transformation of power/political and personal change, social action and community capacity building are applied as a lens to explore this project.
\end{abstract}

\section{Introduction}

This paper presents the description and structural social work analysis of an action research project. It is designed to identify factors that encourage or impede the engagement of marginalized young people in the social policy life of their communities. The project was conceptualized and undertaken within a provincial context characterized by the erosion of community sustainability due to social economic disadvantage and outmigration. The purpose of the project ultimately is to strengthen communities by enhancing participation of excluded youth in social policy development. In particular, it presents the development and pilot testing of an educational workshop that facilitates the enhancement of skills and awareness of youth regarding social policy. The project emerged from a belief that the depth and breadth of the social capital base in communities can be enriched when youth gain an increased understanding of the role and impact of social policy at local, regional, provincial, and national levels. The 
workshop design provides an opportunity for the young people to operationalize their new knowledge and awareness by developing a Social Policy Action Plan (SPAP) to address a policy issue of concern in their local community.

\section{Review of the Literature}

For the purpose of this project social policy was defined for the youth as, "the rules for living in five dimensions or spheres of society which make it possible for people to live in a cooperative and satisfying manner." This concept was further simplified for the youth, defining it as, "a range of rules which affect a person socially" - such as a curfew at home, speed limits, alcohol age limits. Community development in this study is described as the empowerment of youth through the provision of knowledge about social policy and guided practical experiences or SPAPS to enable their voice to effect change in their communities. Literature related to youth engagement and structural social work also provide further context for this study.

\section{Youth engagement.}

The working definition and key messages of the Centre of Excellence for Youth Engagement (2009) was adopted in this study. They include: "Youth engagement is the meaningful and sustained involvement of a young person in an activity focusing outside the self." Full engagement consists of a cognitive component, an affective component, and a behavioral component - Head, Heart, Feet.

\section{Key messages of project:}

- Meaningful youth engagement produces benefits to youth and the community in which they live.

- Through engagement, youth gain a sense of empowerment as individuals and make healthy connections with others, which is associated with reduction of risk behaviours and increased participation in positive activities that contribute to community.

- Youth engagement is a cross-cutting, comprehensive, strength-based practice for effective protection, prevention and intervention on multiple issues.

- The community gains from the contributions that youth bring to organizations, activities and their relationships.

In addition, the literature has identified a link between youth engagement and a wide variety of positive outcomes including:

- reduced alcohol use and higher school achievement (Eccles \& Barber, 1999),

- reduced socio-emotional difficulties (Mahoney, Schweder \& Stattin, 2002),

- lower rates of school failure and drop-out (Mahoney \& Cairns, 1997), and

- greater commitment to friends, families, and communities (Center for Excellence in Youth Engagement, 2003).

It also provides data to assist communities in establishing practices that encourage youth engagement. These include:

- providing youth with opportunities for engaging in experiential activities that allow them to make a difference,

- allowing youth to follow their passions and to speak about their experiences, 
- building collaborative and trusting relationships with other youth,

- creating networking opportunities for youth, and

- engaging youth in decision-making (Dumond, Warner \& Langlois, 2003).

The rationale for and design of this project draws substantially on these findings.

Structural social work literature specifically provides an academic context for the conceptualization of the project in terms of its principles and design. The concept of full participatory democracy connotes the social inclusion of all members of a society; in fact, it inherently means that every person is and feels to be a "member" (Falck, 1988). Its existence would preclude marginalization; that is, social/economic/political exclusion of some people by those with power. Each person would hold a social location that genuinely carries a role and a voice in determining policy directions that affect his/her community life.

Lundy (2003) addresses the potential for social work to make a contribution in communities to activate the collective resources of residents toward enhanced strength and sustainability. In addition to social work's "promotion of critical thinking [to assist] members in gaining an understanding of the inequities facing them," is its facility to "engage community members" in goal advancement through "a process of communication among members and between them and the wider community" (p. 175). In communication, they engage in collective consciousness raising, "sharing" their experiences .... What were originally experienced as private, personal problems are now seen in terms of their political dimensions" (Mullaly, 2002, p. 175).

Community capacity building in this personal/political context also is supported by the literature on conflict theory/power distribution which positions such community based work as a challenge to established power (Hustedde \& Ganowicz, 2001).

The objectives and design of this project resonate with Lundy's statement: "Building capacity in communities...helps members to take control of their communities, establishes local leadership, and lays the groundwork for much-needed community resources" (ibid.). Given that the young people involved in this study may remain as lifelong community members, enhancement of their existing skills and development of new competencies for social action to support community sustainability are vital. Out of this personal/political reality and theoretical context, the project was conceptualized, undertaken and presented here through a structural social work lens.

\section{Description of the Project}

In the North Atlantic island province of Canada, the last decade has seen the advent and implementation of several broad ranging policy initiatives, starting with the Strategic Social Plan (Government of NL, 1998) of the 1990s and the nationally recognized Poverty Reduction Strategy (Campaign 2000, 2005). All of these programs include elements intended to address the needs of youth with a focus on the development and expansion of skills toward income security (Government of NL, 2007). The failure of resource-based industries has left communities devastated. For example, the failure of the ground fish industry has resulted in the "leaving behind" of many youth with the least capacity to market them and engage in the civic life of their communities and hence face a future of possible social exclusion from mainstream society.

Project overview. Working with a project coordinator, a group of young people affiliated with the provincial Community Youth Network (CYN), in an urban centre, were recruited and designated as "the Reference Group" (RG). Their roles were to design a youth orientated 
workshop on social policy, to participate in its delivery at four sites across the province, both urban and rural, and to take part in the identification of the resulting learning. The overall project team consisted of the RG, a project coordinator, and the university-based researchers.

Project participants. The target population for this project was composed of two categories of youth, the first being the RG - the youth we designed and delivered the workshop for and the second being the youth who participated in the social policy workshop across the four sites. The RG was comprised of 7 youth ( 2 males and 5 females) average age 16, all attending school. An average of 12 youth participated in each workshop. Overall, all participants faced multiple barriers to their general well-being and future life chances, including high rates of youth poverty, unemployment, literacy difficulties, and very low population density with associated infrastructure limitations. Despite additional challenges for the RG members of limited education, drug and alcohol use, learning disabilities, and absence of positive role models and supports, they sustained their involvement with the project over its full fifteen month duration.

Social policy workshop. At each workshop site the RG organized the other youth participants into "tribes" as part of a Survivor Island Game, as described below. This game format was an original idea contributed by the RG, and all workshop activities took place accordingly.

Throughout the two day workshop there were two streams of activity. The first activity required groups to respond to interpersonal issues within their imaginary communities, e.g., "someone in the community is unable to care for themselves," and then to identify the considerations necessary for the community to live co-operatively. The second activity was a "mapping activity" which introduced the youth participants to concepts of social policy by inviting them to examine policies that impact their actual lives within five spheres: personal, home, school and social environment, local community, and provincial/national. Life size poster outlines of the human body were provided for each tribe to write real time examples of policies relevant to each sphere. Subsequently, a representative of each tribe presented the recorded content to the whole group and attached the "person" onto a wall.

In addition, the workshop was punctuated by various team-building and energizing activities, planned and facilitated by the RG. One was an exercise where participants were asked to complete an inventory of their own community resources. The final exercise was the identification of a Social Policy Action Plan (SPAP) regarding an issue of concern to youth in their local community. Examples included an environmental "clean up" project in a rural northern Aboriginal community and programming at a regional youth resource centre. All workshop activities were characterized by clarity, flexibility, choice, and fun while still engaging youth on the social policy theme. The dynamic of the workshop was fast paced, varied, energetic, interactive, and relevant to the local youth (Sullivan, Sullivan, Hardy Cox, \& Johns, 2008).

Structural social work applications. The theoretical and ideological foundation of the project solidly reflects constructs of structural social work. The project was guided by principles of respect, empowerment, youth inclusion, social self-determination, and a strengths focus (Carniol, 1992; Hustedde \& Ganowicz, 2001; Lundy, 2003; \& Mullaly, 2002). This was supported throughout the "process" of the project in the on-going collaborative model whereby the project team worked together in a dynamic of shared power to design, plan, and present the social policy workshop. Respectful reciprocal feedback became the working culture. 
The relationship that developed between the project coordinator and the RG, were documented in the coordinator's logs as being characterized by teaching, personal guidance, modeling, authenticity and candor, genuine warm acceptance and care, safety, and comfort. The project coordinator consistently reinforced the principle of mutual respect. For example, a clear message was communicated to workshop participants by the RG that "there are no wrong answers." Consequently, the RG adopted it as an essential working concept and incorporated it in the content and dynamics of the workshop. This was illustrated during the workshops when personal issues compromised the ability of certain RG members to stay engaged. At these times, the young person was redirected to an alternative activity, in order to maintain inclusion and facilitate the flow of the workshop. As a result of this attention to process, each RG member ultimately participated in some aspect of the workshop, with each one's abilities making a contribution to the whole endeavour. Some contributed more to the design and content; others to the workshop delivery. RG members variously served as one another's checks and balance and supports. There were many examples of young people helping one another, one being the facilitating of verbal participation of peers when literacy was a barrier.

A comfortable and safe climate was created, particularly evident in the person mapping exercise. Workshop participants often assigned personalities and names to the human forms used in the mapping exercises sometimes based on actual "characters" well known and beloved in the local community. The shared knowledge of these characters enhanced participants' ownership, and enjoyment of the workshop.

At all sites, project team members' demonstrated their cultural sensitivity. This was particularly apparent at an Aboriginal site where English was not the first language of some participants. A team member, who was knowledgeable about Aboriginal issues, was able to provide culturally appropriate support, which appeared to be effective as Aboriginal youth became full participants in the workshop discussions and activities. The social policy workshop design, with its youth centered focus assured by the input of the RG, strongly reflected the underlying project principles of participatory democracy and youth-friendliness. Throughout the project, tangible functional supports were provided in order to facilitate engagement and inclusion. Included for the RG were: access to computers, provision of food, transportation to workshop development sessions, and activities to support their formation as a "team," such as indoor wall climbing and bowling.

For workshop participants, transportation and nutritious food were provided. This served to reduce disparity and also provide time for informal socialization and networking among the youth at each site. All these practical supports served as incentives that further enlivened an already existing sense of enthusiasm among the youth and solidified their engagement in, enjoyment of, and commitment to the project.

\section{Methodology}

Data collection. To track the growth of the work of the RG multiple data sources were utilized:

1) the coordinator submitted a weekly log of on-task activity and relational content,

2) youth feedback was obtained in an independently conducted focus group evaluation,

3) the coordinator consolidated the youth input into various mapping exercises of the workshop groups, 
4) key informant interviews during the summative evaluation and

5) researcher's notes captured routine conference calls with the coordinator and the face to face meetings with the youth at the various workshop sites.

\section{Analysis}

The project and its process exemplifies principles of structural social work, with particular attention to:

1) collective consciousness,

2) unmasking of structures,

3) power sharing,

4) social action and community capacity building, and

5) transformation of power/political and personal change.

(Carniol,1992; Hustedde \& Ganowicz, 2001; Lundy, 2003; Mullaly, 2002). Each principle is explored below:

\section{Collective Consciousness}

From the initial recruitment of the RG members an inclusive "sharing of experience" format was used to generate basic understanding of the intent of the project, new awareness around policy issues, and ultimately the actual content of the workshop. The research team members were challenged to accommodate the cultural diversity and varied developmental functioning/ maturity levels among the youth. However, their capacity for verbal participation and willingness to share their respective views served to integrate their differences into the project experience. For example, brainstorming as an idea-generating technique appeared to be well within their comfort zone and proved fruitful.

The step by step workshop design, started from the personal (self), and moved through the five levels of civil society contributing to the RG youth's awareness about the structures of society. A critical component for the RG youth was being part of the project development process from the beginning - a process which included workshop development and delivery to youth at other CYN sites. Taking such leadership and ownership contributed to the RG's knowledge of social policy. In their geographic region social policy typically fell within the domain of adults having an advanced educational and/or experiential background. Recognition of the young people's ability to provide leadership at various sites and to train peers further reinforced their proprietary perspective of their own knowledge base and rightful role in the social policy context. For example, by the final workshop, the RG members demonstrated their understanding of social policy content by communicating their knowledge of social policy to the workshop participants. The workshop design, development, and implementation served as a living lab illustration of the viability and relevance of youth engaging in the social policy life of their communities. Further, this ownership was affirmed when at the airport after the final workshop, the RG members were overheard explaining their workshop and discussing social policy to an interested bystander!

Relationship served as a means to facilitate collective consciousness. Relationships evolved between the RG and the project coordinator; between youth workshop participants and their local CYN coordinators; among various youth communities; between adult members of the project team and the RG. During pre-engagement phases and ongoing project activities, these 
relationships contributed to creating a safe environment which was evidenced by energetic engagement in the workshops.

2. Unmasking of Structures. Structural social work theory identifies structures in society which impact on individuals. Primary structures include patriarchy, capitalism, ageism, ableism and heterosexism. Secondary structures include family, community and bureaucracy. The workshop design emerged dramatically as a tool used by the young people to unmask the structures of society on the five levels (personal, home, school and social environment, local community and provincial/national) within which social policy or (in youth speak "rules") exists. The thematic approach, the interactive nature of the activities, the small group work, and in particular, the personal mapping activity helped participants to become aware of policies across society, and triggered a beginning understanding of how these policies function and impact upon everyday life. The ideas generated by the youth in the mapping exercises revealed creative, and age and stage appropriate ideas, which in turn created fertile ground for a collaborative learning experience. The collaborative process welcomed the adult team members contributions to the youths' learning by providing where needed some clarity on content and helped contextualize the content to the local community, thus assisting the young people to bridge the workshop content to their local reality.

Despite the challenges, e.g., developmental and maturity disparities for RG members and workshop participants, their learning was facilitated by the design of the workshop in which the sequential exercises built upon one another, making incremental and cumulative learning possible. The young people were curious about what was next and what new clue would be revealed to crystallize their appreciation of social policy. At times, the youth would wonder about the purpose of an exercise, and then as the next one or two steps unfolded, they "got it" - an epiphany of insight was evident and they often were amazed at the connections they were able to see.

3. Power Sharing. From the outset, the adult team members regarded the youth members as full and essential partners in the development and implementation of the project. This was based on a belief that the young people held knowledge that was relevant to achieving the purposes of the work; work from which benefits most effectively could affect their ongoing lives. For example, at the initial information and recruitment meetings to develop the workshop, the RG brainstormed the participant's baseline notions of policy. This appeared to be well within their interest and ability zones as they easily gave abundant examples of aspects of policy drawn from their own life experience such as rules related to loitering, school policies, alcohol and driving.

The workshop design contributed to the sense of shared power in the young people's learning process, both in the workshop development and in the delivery phases. For example the youth took the lead in the development of the workshop and its delivery. Recognition of their own abilities to accomplish the work and to provide leadership at the various sites reinforced their realization of power shared with the adult team members. This is well illustrated by an exchange observed between one of the youth members and a stranger encountered at the airport in Labrador following the final workshop. When asked the purpose of the trip, her response was articulate and accurate, but more importantly passionate and personal. Her comments included details and frequent assertions of ownership such as "we developed ..." and "we delivered ...," language used consistently and with pride throughout the exchange, while her youth colleagues standing nearby nodded their agreement. 
Power sharing was evident in the numerous relationships within the project; each holding some capacity for generating a sense of ownership in the young people which in turn helped them to discover the power within, and the power shared between them and with the adult partners. Across the lifecycle of the project there was a visible track of power sharing which flowed from the principles underlying the project. The sharing of power was exemplified initially in the project design which constructed the project team as comprising youth and adult members. It was seen to continue in the engagement of the youth by the project coordinator in the development of the workshop; in the delivery of the workshop by the RG; and in the final exercise when the local youth participants generated a means to partner with community leaders to refine further and implement their SPAP idea.

It is notable that we encountered almost no attrition in the RG. All seven RG members remained active participants throughout the fifteen months of the project, in spite of frequent crises and numerous obstacles in their lives. This suggests the importance of inclusion, belonging, participation, and ownership that the young people experienced as participants. They truly were members of the team and felt that belonging and centrality to the project.

4. Social Action and Community Capacity Building. Structural social work recognizes the importance of social action to create social change. In this light the workshop was designed to culminate with the identification of a Social Policy Action Plan (SPAP), which entailed an invitation to the youth participants to identify areas in their local communities where they believed change was warranted. For example, in the school and social realm the youth in one particular workshop identified a school policy to institute regular Fast Fridays (on a once monthly basis, to reduce the length of the standard class by 15 minutes to allow for a mid-day dismissal). In the local community realm, they targeted alteration to municipal by-laws regarding loitering. In the provincial/national sphere, improvement in social assistance rates, changes to hunting regulations and decisions regarding the closure of the commercial fishery. The range of these suggestions indicates the breadth and depth of the young people's awareness, and speaks directly to their potential to develop an active citizen role in the sustaining of their communities and perhaps ultimately in a wider context.

Youth suggestions for potential policy work were prioritized, taking into account the feasibility of follow-through. With discussion having proceeded and the desire for regular Fast Fridays selected as a SPAP, the entire workshop group then determined whether it would be necessary to create a new or modify an existing policy. They identified allies in the adult community to engage as active partners in support of their initiative. The group also identified steps in social marketing to achieve the desired change: meeting with the town council, posting flyers, delivering pamphlets, speaking on public service radio and at community meetings, and writing letters to the editor and articles in local newspapers. The final steps in operationalizing the social action project were the identification of a core SPAP team, garnering local organizational support for the work, and establishing a consultation relationship with the research project team. In sum, local communities such as this one, as a result of the RG workshop now had a driving force in their community to address such issues.

5. Transformation of Power/Political and Personal Change. Transformation of power emerging from this project was observed to lie within the two interconnected spheres of personal and political change. Over the course of the year the RG youth acquired and demonstrated their awareness of the power of the "youth voice" in social policy by guiding their peers- the workshop participants- toward the identification of various Social Policy Action Plans (SPAP's). 
The RG youth over the duration of the project discovered and honed such personal attributes as self-confidence, public speaking, poise, creative expression of ideas, problem solving, and ease in cooperative and collaborative team membership. This observed development augers well for the future social policy engagement for contributing to the social policy life of their communities. The transformation of personal power can be seen in the summative reflection of one youth who synthesized his experience with the reflection: "I am proud."

\section{Conclusion}

In sum, the workshop design developed by youth for youth, engaged youth participants through its use of interactive group work that raised their awareness of power possible when people work together toward shared purposes. As this approach to the delivery and processing of social policy content was seen as establishing the ground work among youth who may become the future local leaders, the project can be viewed as a means of building community capacity.

Knowledge is power and the Social Policy Action Plan (SPAP) project provided all the youth participants with the opportunity to learn about the structures of society and the roles they can play to maintain or change these structures. It is anticipated that the lessons learned, and more poignantly, the sense of personal and collective power, ability, and agency to effect communitybased social policy, will endure in these young people as they carry out their citizen roles through adulthood.

We recommend that other agencies working with youth within a capacity building framework apply the fundamental principles of structural social work as outlined here. As identified and reinforced in Sullivan \& Sullivan (2010) and Sullivan et al. (2008, 2010), the primary factor found to have engaged the youth in policy work was the foundational belief that youth have a right to a voice on the social policy issues of their communities, and that they possess the strengths and skills to implement effective social policy action plans.

\section{References}

Campaign 2000. (2005). Decision time for Canada: Let's make poverty history. Retrieved November 2, 2009, www.campaign2000.ca/rc/rc05/05NationalReportCard.pdf

Carniol, B. (1992). Structural social work: Maurice Moreau's challenge to social work practice. Journal of Progressive Human Services, 3(1), 1-20.

Center for Excellence in Youth Engagement. (2003). Youth engagement and health outcomes: Is there a Link? Retrieved November 2, 2009, http://www.tgmag.ca.

Centre of Excellence for Youth Engagement. (2009). Definition and key elements of youth engagement. Retrieved November 2, 2009, http://www.tgmag.ca/index e.htm relationships. $\underline{2009}$

Dumond, C., Warner, A., \& Langlois, M. (2003). Voices from youth teams: How to create successful partnerships for community action. Halifax: Heartwood Institute. 
Eccles, J., \& Barber, B. (1999). Student council, volunteering, basketball or marching band: What kind of extracurricular involvement matters? Journal of Adolescent Research, 14, 10-43.

Falck, H.S. (1988). Social work: The membership perspective. New York: Springer Publishing Company, Inc.

Government of Newfoundland \& Labrador. (1998). Strategic Social Plan. Retrieved November 2, 2009. http://www.releases.gov.nl.ca/releases/1998/hre/1201n02.htm.

Government of Newfoundland \& Labrador. (2007). Poverty Reduction Strategy. Department of Human Resources Labour and Employment. Retrieved November 2, 2009 http://www.hrle.gov.nl.ca/hrle/poverty/poverty-reduction-strategy.pdf

Hustedde, R., \& Ganowicz, J. (2001). The Basics: What's essential about theory for Community development practice? Journal of Community Development and Society 33(1), 1-19.

Lundy, C. (2003). Social work and social justice: A structural approach to practice. Peterborough: Broadview press.

Mahoney, J., \& Cairns, R. (1997). Do extracurricular activities protect against early school dropout? Developmental Psychology, 33, 211-253.

Mahoney, J., Schweder, A., \& Stattin, H. (2002). Structured after school activities as a moderator of depressed mood for adolescents with detached relations with their parents. Journal of Community Psychology, 30(1), 69-86.

Mullaly, B. (2002). Challenging oppression: A critical social work approach. Toronto: Oxford University Press.

Sullivan, N. \& Sullivan, E.M. (2010). Creating connections among disadvantaged youth toward participation in policy development for social change. In M.Cohen, L. Berman-Rossi \& H. Fischer-Engel (Eds.), Creating connections: Celebrating the power of groups. London, England: Whiting \& Birch.

Sullivan E.M., Sullivan, N., Hardy Cox, D., Butt, D., Dollemont, C. \& Shallow, M. (2010). 'You are taking who?! to a national conference on social policy?': A place for youth in the social policy life of their communities. Community Development Journal- Advance Access published online on February 26, 2010.

Sullivan, E.M., Sullivan, N., Hardy Cox, D., \& Johns, A. (2008). Way Out There: Youth engagement in social policy action planning. In A.R. Vollman, E.T. Anderson, J. McFarlane, Canadian Community as Partner: Theory and Multidisciplinary Practice (2nd ed., pp. 449 - 459). Philadelphia: Wolters Kluwer Health.

(C) Copyright of Journal of Youth Development Bridging Research and Practice. Content may not be copied or emailed to multiple sites or posted to a listserv without copyright holder's express written permission. However, users may print, download or email articles for individual use. 